International Journal of Engineering \& Technology, 7 (1.9) (2018) 225-228
International Journal of Engineering \& Technology
WPC
Website: www.sciencepubco.com/index.php/IJET
Research paper

\title{
Fabrication of floor cleaner using Wi-Fi module
}

\author{
N. Pugazhenthi ${ }^{1 *}$, P. Venkata Sai Reddy ${ }^{2}$, M. Akash Reddy ${ }^{3}$ \\ ${ }^{1}$ Asst. Professor, Department of Mechanical Engineering \\ ${ }^{2} 1^{\text {st }}$ Year Student, Department of Electronics and Communication Engineering \\ ${ }^{3}$ Vel Tech Rangarajan Dr. Sagunthala R\&D Institute of Science and Technology, Avadi, Chennai, Tamil Nadu, India \\ *Corresponding author E-mail: pugal24@ gmail.com
}

\begin{abstract}
There are a number of machines available now for floor cleaning. In that many, used for a specific purpose like mopping, vacuum cleaning and combination of both. But all these are operated manually with the help of humans. Nowadays, the technology has developed a lot and a new invention has come to overcome the existing model. Earlier, the moping and vacuum cleaner are combined with a single machine for cleaning the floor. This machine was big and operated manually with human with the continuous movement. But in this project, the movement with the machine was stopped and operated using Wi-Fi signal. With the help of circuit connections, this model was developed in a compact manner for floor cleaning. This floor cleaning machine was designed simply and can be handled very easily by everyone. This helps the people to clean the floor easily in every part of the area by sitting in a place. Here we used Arduino mega 2560 for controlling the working of this machine.
\end{abstract}

Keywords: Arduino; Circuit; Floor Cleaner; Wi-Fi; Machine.

\section{Introduction}

Generally, cleaning the floor is a daily routine task carried out by every person in day-to- day life. Even though the technology is developing, but the way of cleaning is same as like cleaning by a human (moping, dust collecting). The technology is developed up to the system of cleaning with different works like a separate machine for dust collecting \& moping [1]. By using moping machine, it cleans the dust of small quantity. Those machines are in huge size \& very expensive. So that by implementing the technology and modifying the floor cleaning machines into a new manner [2]. By combining both moping and dust collecting in a same machine to make a new one. The project makes a prototype of a small high technology floor cleaning machine. In this project both sweeping and moping processes take place simultaneously. The entire project is controlled by an Arduino mega 2560 and WiFi Modula Node-MCU. The Arduino Mega is a microcontroller board based on the ATmega1280. The project is capable of cleaning dust and moping at the same time of working. In the earlier machines the working is different and it takes some time to do the complete work of cleaning the floor. It makes the people to spend the time for cleaning their floors and also the maintenance of those machines is somewhat difficult. So by taking these issues, the machine is modified into new one, in this, both works will take simultaneously and maintenance is also simple and easy to use. Peoples can enjoy by operating this machine [3]. This project is designed especially for household purpose.

\section{Materials \& method}

\subsection{DC motor}

A DC motor converts the electrical energy into mechanical energy. It produces torque by using both electricity and magnetic fields. It is used to carry the entire load of the machine. It takes an action to move the machine forward \& backward directions. It is connected to the wheel and it is fixed on the base (acrylic sheet) of the machine. DC motor have different types of rpms and based on their functions and mentioned below [4].

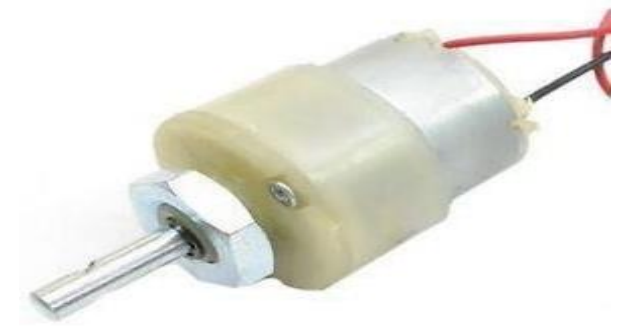

Fig. 1: DC Gear Motor.

\subsection{Water pumping motor}

These motors are used to transverse the water from one place to another place by applying force and this process was carried through electrical energy. Here, we are fixing a high pressure $12 \mathrm{~V}$ DC Water pump in this machine for supplying water from the container to the ground by using a pipe [5]. This motor is fixed to the container and the power supply to this motor is supplied from the Arduino. 


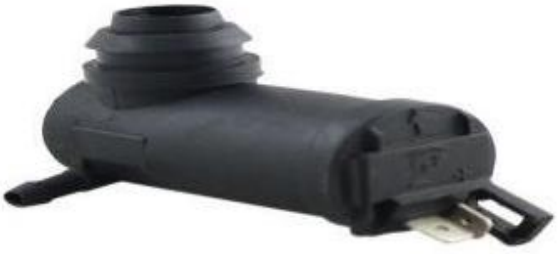

Fig. 2: Water Pumping Motor

\subsection{Sweeping machine}

This sweeper machine does a couple of jobs at a time, it cleans the floor surface and takes the dust into dust collecting pan inside the sweeper machine. This sweeping machine uses mechanical principles [6]. This machine is used as a vacuum cleaner in this project. It is fixed at the front portion of the project as shown in the figure. This sweeper machine first catches the dust and place that dust in the empty box inside the machine. After sucking the dust, the backside of the cloth cleans the floor. The entire working places are shown in figure.

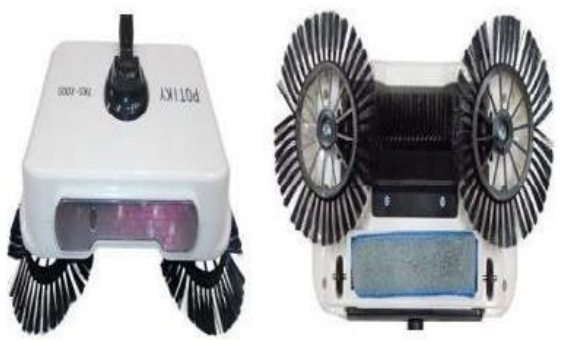

Fig. 3: The Sweeper Machine.

\subsection{Acrylic sheet}

It is synthetic fibre board and it is made from a polymer. It is very light weight than wood and also stronger than it. It can bear the load more than the wooden board. So, we are using it as a base of the project than the wooden board.

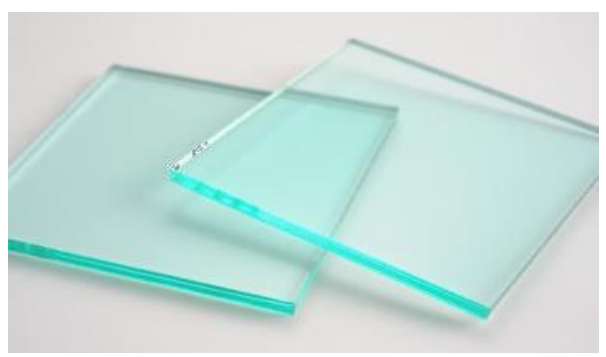

Fig. 4: Acrylic Sheet

\subsection{Water container}

Containers are used to store different things based on the materials. We are using water as a material, so the container is called as water containers. We have chosen a cuboidal shape of the container for the storage of water.

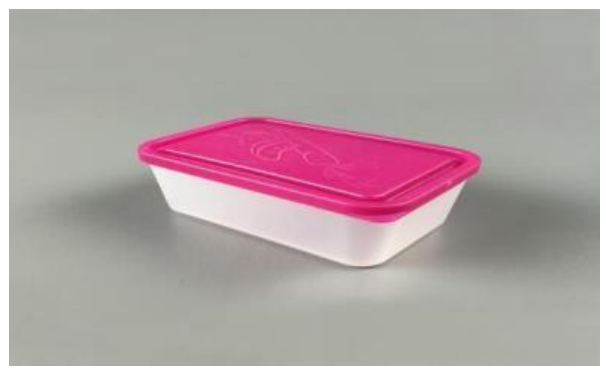

Fig. 5: Water Container.

\subsection{Arduino}

Basically Arduino are of different types based on the usage. We are using the ARDUINO MEGA 2560. The MEGA 2560 is designed for more complex projects, with 54 digital pins and 16 analog input pins. This mega 2560 makes your projects on basically controlled in household works. It has 54 digital Input/ Output pins in those, 15 can be used as Pulse Width Modulation (PWM), 16 analog inputs, 4 Hardware serial ports (UARTs), A 16 MHz crystal oscillator, a USB connection, a power jack, an ICSP (in-circuit serial programming) header, and a reset button. It is simply connected to a computer with a USB cable or power it with a AC-to-DC adapter or battery to get started. And the program required to the machine is installed by using a USB cable to the computer. In those 54 digital pins, we are used just 10 pins (22-40) for controlling the machine. In those pins 4 are connected to the Wi-Fi module and the remaining 6 is connected to the relay boards. The $12 \mathrm{~V}$ DC power supply is provided to the Arduino mega 2560 from this Arduino, power is supplied to the Wi-Fi module.

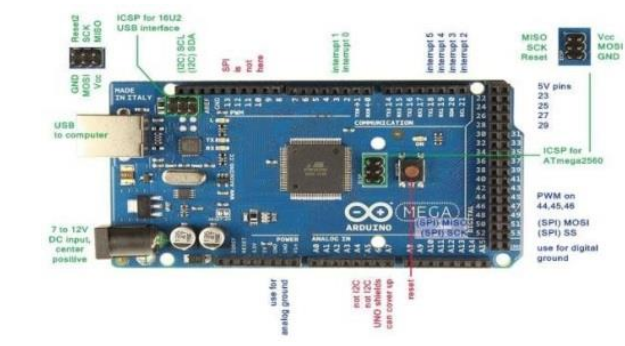

Fig. 6: Arduino Mega 2560 Pins Configuration.

\subsection{Wifi modula-node mcu}

It is an ESP8266, This small module allows the micro controller to connect a Wi-Fi network and makes IP address based connection to mobile, and the machine is controlled by the commands on mobile given in the app (ESP8266 CONTROLLER). It is used to control the entire machine by giving commands on smart phone and it is connecting based on the internet connections. The network, which should connect is fixed \& it will connect only to a single network, that network details is programmed in that ESP8266 module. The power supply comes to this esp8266 is from the Arduino mega 2560 and the power input to this module is $3.3 \mathrm{~V}$ only. In this module we are connecting just 4 pins to the Arduino and 2 power pins [7].

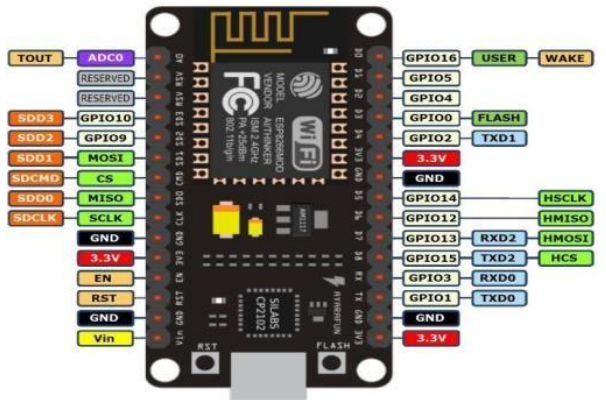

Fig. 7: Esp8266 Wi-Fi Module.

\subsection{Relay circuit board}

Relays are used mostly interfaced with micro controllers and digital systems. But micro controller usually cannot provide enough current to drive relays. Micro controller's pins usually provide maximum current of 1-2 Ma per pin which is not enough to operate the relay. The circuits which are used to drive relays are called relay driver circuits [8]. Therefore the relay driver circuits using ULN2003 are used to drive relays. We are using 3 relay boards, out of the three, one is connected to a pumping system of water to 
clean the floor and another 2 are connected to the wheel of the machine, and the operation of this is controlled by the Arduino mega

2560 .

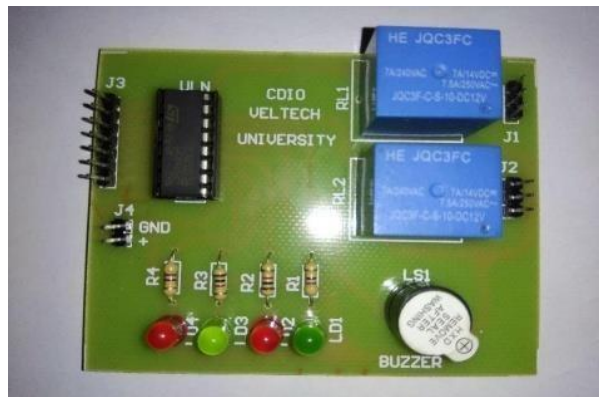

Fig. 8: Relay Circuit Board.

\section{Method}

First, we have to make the base of the machine by using acrylic board of required dimensions $(500 \times 300 \times 8 \mathrm{~mm})$. With the help of the L-shaped clamps, base and the $12 \mathrm{~V} \mathrm{DC}$ motor are connected. The wheels are connected to the motor and it is fixed to it. After making the base, we have to make a hole in the front portion of the base, at a distance around $14-18 \mathrm{~cm}$ from the front of the base.

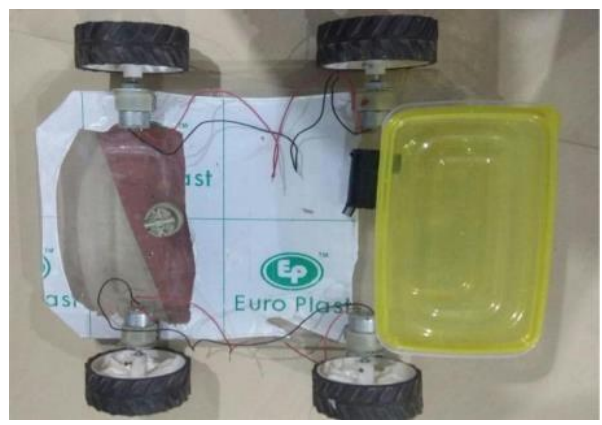

Fig. 9: Base of the Machine.

After making a hole we have to fix a motor at that place and bottom of the base, we have to fix a scrubber to clean the floor. Completion of these things we have to take the water pumping motor and it is fixed at the bottom of the container and the entire setup is fixed at the backside of the base. By fixing these things the entire base part is completed. We have to prepare or buy the relay board which are used to connect the wheels and the Arduino after getting these relay boards keep it separates and makes the program to the Arduino mega 2560 and check whether the Arduino is working properly or not before giving coding to it. After completing the coding to the Arduino check again, whether the coding is working properly or not. Now we have to give the coding to the ESP8266 and make sure that the network details perfectly and run the coding completely. After completing the coding to the boards make sure the perfect connections before giving the power supply to the Arduino in connections. And fix the entire circuit connections safely and fix at the top of the machine [9].

The main thing is left to connect the machine is that the sweeper machine (vacuum cleaner), and thing is fixed at the front portion of the machine and it fixed to the base of the machine. After fixing these thing the machine is ready to do its job. By giving power to the Arduino by using $12 \mathrm{~V}$ DC battery.

\section{Result and disscussion}

In this type of machines the main role takes place in the circuit connections. The blog diagram of the project is shown above figure. From that we can understand that controls of the machine.
The ARDUINO is interconnected to the ESP8266 and also with the relay modules and the commands are given in the ARDUINO are displayed on the LCD screen. And the connection is shown below clearly.

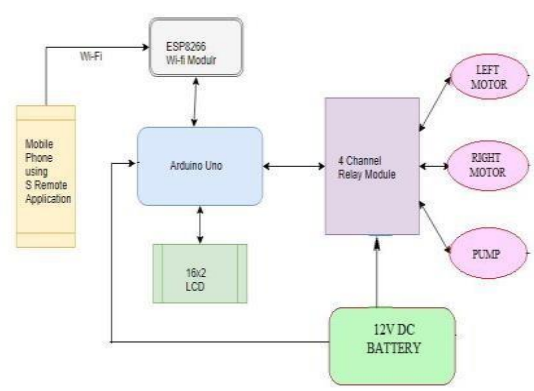

Fig. 10: Block Diagram of the Controlling Unit.

The connections are in between the Arduino and the ESP8266. In that the $3.3 \mathrm{~V}$ pin of ESP8266 is connected to the $3.3 \mathrm{~V}$ pin of ARDUINO in the power pins. And the ground pin of the ESP8266 is connected to the ground pin in ARDUINO in the place of digital ground pin position. The pins 22, 24, 26, 28 of ARDUINO are connected to the D8, D7, D6, D5 the pins of ESP8266 respectively.

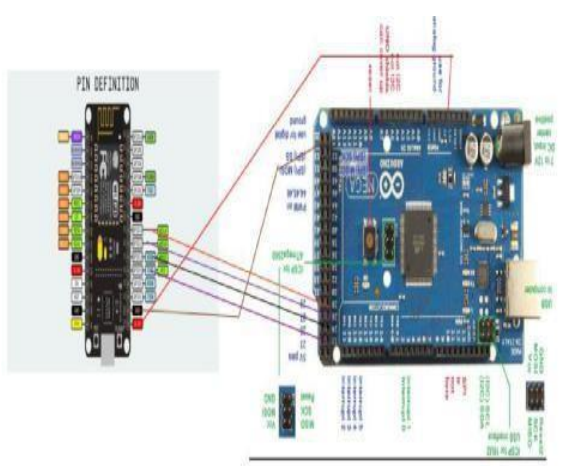

Fig. 11: Connections between Arduino and Esp8266.

The power to the ESP8266 is getting from the Arduino and the maximum input of the power is $3.3 \mathrm{~V}$ to the ESP8266. The power to ARDUINO is getting from the battery of $12 \mathrm{~V}$, and it is connected to the Arduino at the power supply position. And the connection between the relay and the ARDUINO is shown below. In figure 12 , the connections are in between the Arduino and the relay modules. The pins of the $30,32,34,36,38$, and 40 are connected to the relay module pins of different relay modules. The some of the pins of the relay are connected to the DC gear motors. The analog pins are connected to the LCD display. The entire circuit is based on the Arduino and the ESP8266, and the entire control of the machine is on the hands of the ESP8266, and it is connected to the Arduino, based on the network communication (signal strength).

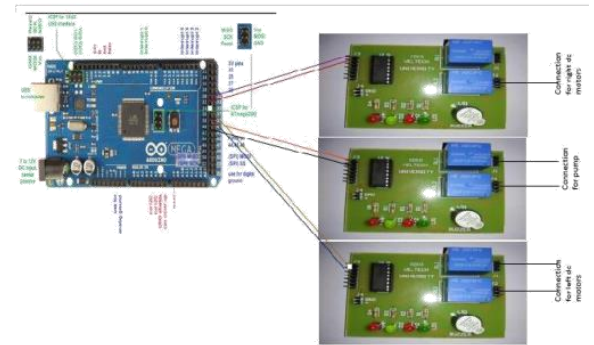

Fig. 12: The Connection of Arduino and Relay Modules.

In figure 13, indicates the final prototype of floor cleaning machine which contains moping and vacuum cleaner in a single machine for cleaning the floor. 


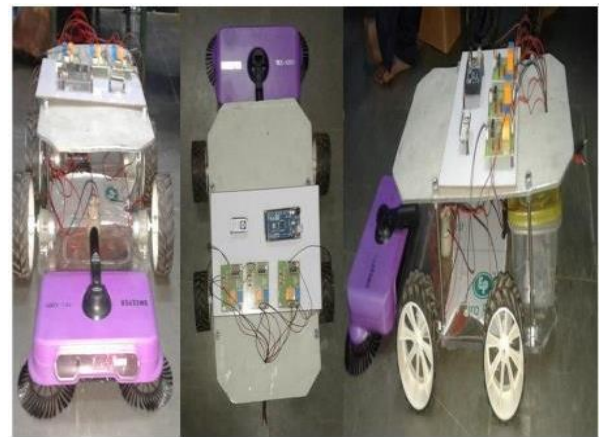

Fig. 13: The Entire out Look of the Model.

\section{Conclusion}

Here I conclude, that the model was created for cleaning the floor through electronic components. These were controlled and operated through Wi-Fi module. This model can be used by a human and they can operate the machine by sitting in a place. This was designed in a compact manner. So, this was used to clean the floor in even in smaller area.

\section{References}

[1] Vaibhavi Rewatkar, A Review on Design of Automated Floor Cleaning System, International Journal on Recent and Innovation Trends in Computing and Communication ISSN: 2321-8169 Volume: 3 Issue: 2 120- 122, 2012.

[2] Sahil Bharti, Design and Development of Cleaning System, International Journal of soft computing and Artificial Intelligence, ISSN 2321-404X, 2013

[3] Rajesh, M., and J. M. Gnanasekar. "Path Observation Based Physical Routing Protocol for Wireless Ad Hoc Networks." Wireless Personal Communications 97, no. 1: 1267-1289. (2017)

[4] Ajay P John, Implementation of an Automated Smart Robotic Floor Cleaner, International Journal of Advanced Research in Electrical, Electronics and Instrumentation Engineering, Vol. 6, Issue 4, 2017.

[5] Karthick.T, Simple Autonomous cleaner Robot, International Journal of Science, Engineering and Technology Research (IJSETR), Volume 4, Issue 5, 2015.

[6] Rajesh, M., "A Review on Excellence Analysis of Relationship Spur Advance in Wireless Ad Hoc Network." international Journal of Pure and Applied Mathematics Volume 118 No. 9, 407-412, 2018.

[7] Manya Jain, Automatic Floor Cleaner, International Research Journal of Engineering and Technology, Volume: 04 Issue: 04, 2017.

[8] Abhishek Pandey, A Technological Survey on Autonomous Home Cleaning Robots, International Journal of Scientific and Research Publications, Volume 4, Issue 4, 2014

[9] Satyinder Singh, Robotic Vacuum Cleaner, International Journal of Engineering Science and Computing, Volume 7 Issue No.5. 